\title{
The Utility of the Hypsarrhythmia Paroxysm Index and Sleep Spindles in EEG for Predicting Cognitive Outcomes in a Case Series of Infantile Spasms
}

\author{
Altunel $\mathbf{A}^{1^{*}}$, Altunel EO ${ }^{2}$ and Sever $\mathbf{A}^{3}$ \\ ${ }^{1}$ Department of Neurology, Cerrahpasa Faculty of Medicine, Istanbul University, 34098 Fatih, Istanbul, Turkey \\ ${ }^{2}$ Psychiatrist, Suadiye Mah, Ülkü Sok. No: 17/1, Kadıköy, Istanbul, Turkey \\ ${ }^{3}$ Department of Radiology, Kadıköy Florence Nightingale Hospital, Bagdat Cad No: 63, 34724 Kadıköy, Istanbul, Turkey
}

*Corresponding author: Attila Altunel, Mustafa Kemal Pasa Cad, Deniz Sarayı Apt 49/7, Aksaray, Fatih, Istanbul, Turkey, Tel: +90 5368843649, Fax: +90 2126320025, E-mail: attilaaltunel@gmail.com

Received date: September 03, 2015; Accepted date: October 13, 2015; Published date: October 20, 2015

Copyright: $\odot 2015$ Altunel A et al. This is an open-access article distributed under the terms of the Creative Commons Attribution License, which permits unrestricted use, distribution, and reproduction in any medium, provided the original author and source are credited.

\begin{abstract}
Objectives: Among patients with West Syndrome (WS), the underlying brain dysfunction is considered to be the major determinant of cognitive outcome. However, regardless of whether the WS type is symptomatic or cryptogenic, patients with infantile spasms may have a favourable or grim prognosis. The purpose of this study was to utilize electroencephalography (EEG) to guide treatment, and to assess cognitive outcome.

Methods: We retrospectively reviewed the clinical and sleep EEG data in 16 patients who received adrenocorticotropic hormonal therapy between 2002 and 2014. The hypsarrhythmia paroxysm index (HPI), the frequency or duration of hypsarrhythmia paroxysms in non-rapid eye movement (NREM) sleep, and sleep spindles were evaluated in groups constituted according to etiology.

Results: Cryptogenic patients whose onset of spasms began after 3 months of age and who experienced a shorter treatment delay had preserved spindles and favourable cognitive outcomes. Sleep spindles disappeared in cryptogenic patients with an early onset of spasms, long treatment delay, and high HPI at referral; their neurodevelopmental prognosis was unfavourable. In symptomatic cases in which the age of onset of spasms was earlier than 3 months and there had been a short treatment delay, sleep spindles never fully evolved, and the prognosis was poor. Patients with corpus callosum hypogenesis, a relatively mild malformation, had high HPI values at referral. While two of these patients did not display spindles during the follow-up, three had reappearing spindles as $\mathrm{HPI}$ values diminished, and the outcome was less severe in these patients.
\end{abstract}

Conclusion: This study highlights the significance of EEG in studies of the prognosis of infantile spasms and demonstrates an objective approach that utilizes concurrent evaluation of sleep spindles and HPI.

Keywords West syndrome; Infantile spasms; EEG Sleep spindles; ACTH; Neurodevelopment; Prognosis; Outcome

\section{Introduction}

Neurodevelopmental outcome in West Syndrome (WS) is generally poor, despite therapy. Although some patients with infantile spasms (IS) appear to have a better prognosis, the risk of developing cognitive deterioration remains high for most patients. Despite the many parameters being considered, the underlying brain dysfunction is still believed to be the major determinant of outcome [1,2], and cryptogenic patients experience a good prognosis [3].

The etiology, however, is usually not amenable to change or treatment, and therefore is of limited practical clinical value. In addition, Guzetta et al. [4] found that regardless of whether the WS is symptomatic or cryptogenic, some patients with IS were confirmed to have a favourable outcome. Many studies have revealed that the outcome for cryptogenic patients also remained poor [5-7]. Moreover, early treatment may help prevent subsequent cognitive impairment in both types of WS.
Additional markers are needed both to guide treatment of WS and to better predict the ensuing neurodevelopmental outcome. Our previous study [8] suggested that the hypsarrhythmia paroxysm index (HPI) could be used as an EEG parameter to guide treatment. Among the outcome parameters studied, lag time and initial response to treatment, age of spasm onset, psychomotor status at presentation, recurrence of spasms, and hypsarrhythmia are the most prominent [3,5,9-11], but the number of studies remains limited. Studies on sleep spindles are of interest in the context of the present study, although these are even more scarce $[9,12,13]$.

The hallmark of stage II NREM sleep, sleep spindles consist of waxing-and-waning $11-$ to $15-\mathrm{Hz}$ thalamocortical oscillations, lasting $0.5-3 \mathrm{sec}$ [14]. Spindle evolution was first summarized by Metcalf and Jordan [15], and Hagne [16]: Rudimentary spindles may be seen in the first weeks of life and become fully developed by 12 weeks. While the absence or reduction in the number of spindles has been mentioned as a possible indicator of abnormal brain maturation, their lifelong presence in healthy human beings validates their use as a marker in many pathological conditions. Among those are disorders of consciousness [17,18], stroke [19], encephalopathies [20], phenylketonuria [21], schizophrenia [22], and mental retardation [23]. 
Page 2 of 5

Because spindle activity was associated with maturation in healthy brain development, and was a useful index of cognitive function [24] and deterioration in many neuropsychiatric disorders [25,26], we assumed that it could also be a practical tool in determining the outcome in IS. In this retrospective chart study, we investigated spindle density and HPI in relation to cognitive impairment.

\section{Methods}

We conducted a retrospective chart study by retrieving the medical records of 18 consecutive patients (aged 7.5-72 months) with the diagnosis of IS. The diagnosis of IS was based on the descriptive clinical history of spasms and the presence of hypsarrhythmic activity in sleep EEG recordings. Patients who never received adrenocorticotropic hormonal therapy (ACTH) were referred to our private office between 2002 and 2014. Except for six patients who received ACTH as initial therapy, all other patients were previously treated with various anticonvulsive and antiepileptic drugs at other clinics; however, seizure cessation was not achieved. Both patients with cryptogenic and symptomatic WS were included. The distinction was based on MRI and laboratory screening tests. One patient who had meningitis and another who had severe head trauma during the medical follow-up were excluded from the study.

Information regarding gender, age at onset of ACTH therapy, times of follow-up, treatment delay, developmental assessment at referral and at the end of the follow-up period, presence of other seizures, and relapse of spasms were recorded for each patient. Treatment delay is defined in Table 1. Clinical assessment of developmental deterioration (Table 1) was performed at ages $0-5$ years, using behaviour; object manipulation, gross motor development, and visual attention test items. After age five, patients were evaluated for their academic capability to assess cognitive outcome [5].

Experienced in paediatric epileptology, one of the authors of this study examined all of the EEG recordings. The international 10-20 electrode placement system was used for all EEGs, which were recorded digitally in several programs, including both unipolar and bipolar, and in both vertical and horizontal montages. Sleep EEGs, encompassing a minimum of $30 \mathrm{~min}$ NREM sleep, were recorded without sedation upon referral and at follow-up visits. In order to prevent relapse, we attempted to maintain countable HPI (Table 1) below $2-3 / \mathrm{min}$ by treating patients with short courses of ACTH (7-15 days; $0.03 \mathrm{mg} / \mathrm{kg} /$ day) when necessary. Upon reaching approximately $10 / \mathrm{min}$, cHPI values appeared to decrease and lost feasibility due to the increasingly frequent hypsarrhythmia paroxysms that merged with the succeeding paroxysms.

Durational HPI (dHPI) was calculated at this point (Table 1). A full description of the method and its evaluation has been published elsewhere [8]. The presence or absence of sleep spindles on EEGs recorded previously at other centers, as well as those on our initial and subsequent recordings were noted. If present, sleep spindles were detected visually. Seven patients with cryptogenic IS were evaluated under two subgroups ( $\mathrm{C} 1$ and $\mathrm{C} 2$ ), according to treatment delay. Patients with symptomatic IS $(n=9)$ were subdivided according to the underlying brain dysfunction.

Because of the small group sizes, statistical analysis could not be accomplished in this study. The study was conducted in accordance with the Institutional Review Board regulations.

\begin{tabular}{|c|c|}
\hline Terms & Definitions \\
\hline Treatment delay (TD) & $\begin{array}{l}\text { The period between the initial onset of ISs and the start } \\
\text { of ACTH therapy }\end{array}$ \\
\hline \multirow{4}{*}{$\begin{array}{l}\text { Assessment of } \\
\text { developmental } \\
\text { deterioration (for ages } \\
0-5 \text { years / for ages } \\
>5 \text { years) }\end{array}$} & None: normal development / regular school \\
\hline & $\begin{array}{l}\text { Mild: decreased smiling, alertness and interest in the } \\
\text { surroundings / regular school with support }\end{array}$ \\
\hline & $\begin{array}{l}\text { Marked: diminished eye contact, response to sound } \\
\text { vocalization, and object manipulation / special } \\
\text { education school }\end{array}$ \\
\hline & $\begin{array}{l}\text { Severe: absent smiling, eye contact, interest, } \\
\text { manipulation and spasticity or hypotonia / uneducable }\end{array}$ \\
\hline $\begin{array}{l}\text { Hypsarrhythmia } \\
\text { paroxysms (HPs) }\end{array}$ & $\begin{array}{l}\text { High-voltage (generally }>200 \mu \mathrm{V} \text { ) slow waves with } \\
\text { variable amplitude; spikes and sharp waves from many } \\
\text { foci, and varying with time; and a lack of synchrony, } \\
\text { with a generally chaotic appearance }\end{array}$ \\
\hline $\begin{array}{l}\text { Countable } \\
\text { hypsarrhythmia } \\
\text { paroxysm index } \\
\text { (cHPI) }\end{array}$ & $\begin{array}{l}\text { Number of HPs in NREM sleep divided by NREM } \\
\text { duration (min) }\end{array}$ \\
\hline $\begin{array}{l}\text { Durational } \\
\text { hypsarrhythmia } \\
\text { paroxysm index } \\
\text { (dHPI) }\end{array}$ & $\begin{array}{l}\text { Total duration of the HPs during NREM sleep } \\
\text { calculated as the percentage of NREM sleep time }\end{array}$ \\
\hline \multicolumn{2}{|c|}{$\begin{array}{l}\text { TD, treatment delay; ISs, infantile spasms; ACTH, adrenocorticotropic hormone; } \\
\text { HPs, hypsarrhythmia paroxysms; cHPI countable hypsarrhythmia paroxysm } \\
\text { index; NREM, non-rapid eye movement; dHPI, durational hypsarrhythmia } \\
\text { paroxysm index. }\end{array}$} \\
\hline
\end{tabular}

Table 1: Definitions of some of the terms used in the study

\section{Results}

The 16 subjects in this case series consisted of 6 male and 10 female patients. We analysed 263 EEGs, of which 206 were recorded in our office, and 57 were previously recorded in other laboratories. Patients with cryptogenic IS were classified into two subgroups, C1 and C2, according to the age at onset of spasms (Table 2). Magnetic Resonance Imaging (MRI) results revealed severe perinatal hypoxic ischemic encephalopathy (S1) in two patients, agenesis of corpus callosum (S2) in two patients, and hypogenesis of corpus callosum (S3) in five patients. Patients with hypogenesis of the corpus callosum has similar age of onsets were further subdivided into two groups according to treatment delay (S3a, treatment delay > 1year; and S3b, treatment delay $<1$ year). The characteristics of the patients are summarized in Table 2.

During the follow-up period, 89 EEGs were recorded and ACTH was repeated 54 times in the four patients in Group C1. All of the 89 EEG recordings displayed frequent $(\geq 2 / \mathrm{min})$ sleep spindles. No spasm relapses occurred in three patients, and these patients attended regular schools. The fourth child missed his scheduled EEG recording sessions and his EEGs were recorded only when spasm relapses occurred. The duration of hypsarrhythmia subsequent to spasm recurrences was $\leq 1$ month (cHPI $=4-10.4 / \mathrm{min})$. This patient had normal motor development and comprehension, but was unable to speak. 


\begin{tabular}{|c|c|c|c|c|c|c|c|c|c|c|c|c|}
\hline Case no & WS type & $\begin{array}{l}\text { Age at } \\
\text { onset } \\
\text { (months) }\end{array}$ & $\begin{array}{l}\text { Age at } \\
\text { onset of } \\
\text { ACTH } \\
\text { (months) }\end{array}$ & $\begin{array}{l}\text { Treatment } \\
\text { delay } \\
\text { (months) }\end{array}$ & $\begin{array}{l}\text { cHPI (/min) } \\
\text { or } \\
\text { dHPI (\%) at } \\
\text { onset of } \\
\text { ACTH }\end{array}$ & $\begin{array}{l}\text { SS on } \\
\text { previous } \\
\text { EEG if } \\
\text { present }\end{array}$ & $\begin{array}{l}\text { SS on } \\
\text { our } \\
\text { initial } \\
\text { EEG at } \\
\text { onset of } \\
\text { ACTH }\end{array}$ & $\begin{array}{l}\text { Relapse of } \\
\text { spasms }\end{array}$ & $\begin{array}{l}\text { Post- } \\
\text { treatment } \\
\text { HPI }\end{array}$ & $\begin{array}{l}\text { Post- } \\
\text { treatment } \\
\text { SS }\end{array}$ & $\begin{array}{l}\text { Cognitive } \\
\text { outcome } \\
\text { at final } \\
\text { visit }\end{array}$ & $\begin{array}{l}\text { Age at final } \\
\text { visit (months) }\end{array}$ \\
\hline \multicolumn{13}{|c|}{ C1: Cryptogenic cases with age at onset $>3$ months } \\
\hline 1 & C & 5.5 & 7.5 & 2 & $\begin{array}{l}10 / \min \\
(30 \%)\end{array}$ & - & Yes & No & $<3 / \mathrm{min}$ & Yes & None & 144 \\
\hline 2 & C & 6 & 8 & 2 & $8 / \min (24 \%)$ & - & Yes & No & $<3 / \min$ & Yes & None & 54 \\
\hline 3 & C & 6 & 8 & 2 & $9 / \min (27 \%)$ & - & Yes & No & $<3 /$ min & Yes & None & 54 \\
\hline 4 & C & 7 & 12 & 5 & $\begin{array}{l}21 / \min \\
(65 \%)\end{array}$ & - & Yes & Yes & $4-10.4 / \mathrm{min}$ & Yes & Mild & 60 \\
\hline \multicolumn{13}{|c|}{ C2: Cryptogenic cases with age at onset $<3$ months } \\
\hline 5 & C & 1.5 & 4 & 2.5 & $100 \%$ & Yes & No & No & $<3 / \min$ & No & Marked & 8 \\
\hline 6 & C & 2 & 16 & 14 & $100 \%$ & Yes & No & No & $<3 / \min$ & No & Severe & 30 \\
\hline 7 & C & 2 & 50 & 48 & $100 \%$ & Yes & No & No & $<3 / \min$ & No & Severe & 60 \\
\hline \multicolumn{13}{|c|}{ S1: Symptomatic severe perinatal hypoxic ischemic encephalopathy } \\
\hline 8 & S & 9 & 10 & 1 & $100 \%$ & $\begin{array}{l}\text { Not } \\
\text { reported }\end{array}$ & No & No & $<2 / \min$ & No & Severe & 36 \\
\hline 9 & s & 10 & 11 & 1 & $100 \%$ & $\begin{array}{l}\text { Not } \\
\text { reported }\end{array}$ & No & No & $<2 /$ min & No & Severe & 39 \\
\hline \multicolumn{13}{|c|}{ S2: Agenesis of corpus callosum } \\
\hline 10 & S & 2 & 54 & 52 & $100 \%$ & $\begin{array}{l}\text { Not } \\
\text { reported }\end{array}$ & No & No & $<3 / \min$ & No & Severe & 66 \\
\hline 11 & s & 3 & 72 & 69 & $100 \%$ & $\begin{array}{l}\text { Not } \\
\text { reported }\end{array}$ & No & No & $<3 / \mathrm{min}$ & No & Severe & 84 \\
\hline \multicolumn{13}{|c|}{ S3a: Hypogenesis of corpus callosum with treatment delay > 1year } \\
\hline 12 & $\mathrm{~S}$ & 2.5 & 33.5 & 31 & $100 \%$ & $\begin{array}{l}\text { Not } \\
\text { reported }\end{array}$ & No & No & $<3 / \min$ & No & Severe & 57.5 \\
\hline 13 & s & 5 & 38.5 & 33.5 & $100 \%$ & $\begin{array}{l}\text { Not } \\
\text { reported }\end{array}$ & No & No & $<3 / \min$ & No & Severe & 62.5 \\
\hline \multicolumn{13}{|c|}{ S3b: Hypogenesis of corpus callosum with treatment delay $<1$ year } \\
\hline 14 & $S$ & 2 & 9 & 7 & $60 \%$ & Yes & No & Yes & $4-20 / \min$ & No & Marked & 45 \\
\hline 15 & $\mathrm{~s}$ & 8 & 16 & 8 & $100 \%$ & Yes & No & Yes & $4-26 / \mathrm{min}$ & No & Marked & 64 \\
\hline 16 & $\mathrm{~s}$ & 7 & 18 & 11 & $100 \%$ & Yes & No & No & $<3 / \min$ & No & Severe & 66 \\
\hline
\end{tabular}

Table 2: Patient profiles. WS-West Syndrome; ACTH-Adrenocorticotropic hormone; cHPI-countable Hypsarrhythmia Paroxysm Index; dHPIdurational Hypsarrhythmia Paroxysm Index; SS-Sleep Spindles; C-Cryptogenic; S-Symptomatic

Patients in Group C2 with early ( $<3$ months) onset of spasms had sleep spindles on their initial EEGs recorded in our office at 3, 7, and 10 months, respectively. These patients were later treated at other centers with antiepileptic drugs including vigabatrine, but spasm cessation was not achieved. With the ACTH treatment in our office, despite spasms cessation, sleep spindles were no longer observed on the control EEGs. Sleep spindles disappeared probably long before the treatment onset, otherwise they could reappear.
Patients with severe hypoxic-ischemic encephalopathy (Group S1) had other seizures starting 15-19 days after birth. Their initial EEGs, recorded on 22-80 days after birth had multifocal EEG abnormalities. Countable HPI was lowered to and kept under $2 /$ min and patients were spasm free. Although the treatment delay was only 1 month, HPI was $100 \%$ at referral, and no sleep spindles were observed. Due to the high HPI at referral the possibility of unrecognized spasms, and, thus, delayed treatment cannot be excluded in this group, even though the caregivers claim otherwise. 
In group S2, patients with $>1$ year treatment delays had experienced spasms early ( $\leq 3$ months) in infancy. This group's EEGs, recorded before coming to our office, showed no sleep spindles. Despite low HPI and cessation of spasms without relapse during the follow-up, sleep spindles were not detected.

In group S3a, patients had severe cognitive deterioration despite relatively mild brain malformation. Infants in this group had onset of spasms at $<6$ months, markedly delayed ( $>2$ years) treatment, and high initial HPI values $(\mathrm{dHPI}=100 \%)$. Subsequent to the onset of ACTH, relapses were prevented and HPI remained under $3 / \mathrm{min}$. However, spindles were detected neither on our initial EEG recordings nor on post-treatment EEGs.

Patients in S3b, on the other hand, had initial sleep spindles. One of these patients, with four EEGs recorded before the onset of ACTH, showed frequent $(\geq 2 / \mathrm{min})$ spindles on all of her recordings. On the fourth one, recorded at the age of 6.5 months, she had a relatively high dHPI of $40 \%$ yet still had spindles. When started on ACTH at 9 months, dHPI was $60 \%$ and sleep spindles were no longer detected. The second child in this group also had frequent $(\geq 2 / \mathrm{min})$ spindles in her previously recorded EEGs. When started on ACTH at 16 months, continuous hypsarrhythmia $(\mathrm{dHPI}=100 \%)$ was observed without sleep spindles. During the follow-up sessions with these two children, 42 EEGs were recorded, and ACTH was repeated 15 times. In each patient, sleep spindles reappeared and then disappeared four times. On the EEGs where no spindles were observed, dHPI was $60-70 \%$, particularly prominent in the occipitotemporal regions. Because these two patients were living in other cities, our ability to control HPI was not optimal, and frequent relapses could not be prevented. Still, these patients' cognitive deterioration was less marked than that in patients in other symptomatic groups. The third patient in this group had sleep spindles in five of his previous EEGs. On his initial EEG recording in our office, dHPI was $100 \%$ and showed no spindles. This patient was followed up with $12 \mathrm{EEG}$ recording sessions and ACTH was applied six times. Countable HPI was kept under $3 / \mathrm{min}$ and relapses were prevented; however, sleep spindles did not reappear.

\section{Discussion}

Our retrospective analysis of the prognostic outcome characteristics for infantile spasms was conducted in 16 patients followed between 2002 and 2014. In cryptogenic patients in whom spasm onset occurred after 3 months and treatment delay was $<6$ months, we observed that sleep spindles were preserved, and the cognitive outcome was favourable. We observed that sleep spindles could reappear when cHPI was reduced to under $3 / \mathrm{min}$ following ACTH treatment. The outcome for these patients was less severe. However, regardless of etiology, and despite the subsequently lowered HPI (to $<3 / \mathrm{min}$ ), patients with earlyonset spasms, and/or high HPI at the time of referral had no spindles eventually, and had a poor prognosis.

The findings of prior studies reporting on cryptogenic patients with poor prognosis $[5,7,27]$ are consistent with our results. To these findings, we add that the symptomatic patients with relatively mild brain malformation may also have grim prognosis, and according to patient and treatment characteristics, symptomatic patients with similar etiologies may have different outcomes. Our results also agree with the studies in literature that emphasize the age at onset of spasms and treatment delay as prognostic factors $[5,11]$. When one of these parameters is positive and the other negative in terms of outcome, sleep spindles may provide additional information; a good prognosis is expected if sleep spindles are preserved throughout the follow-up period.

Our observations illustrate that a treatment delay of 7-8 months can destroy the formerly fully developed sleep spindles. If sleep spindles have not disappeared $>7-8$ months before the treatment onset, there is the possibility that they would reappear with efficient treatment. When treatment is further delayed to 11 months the ability to generate spindles is lost permanently. Mori et al. [13] reported similar results in patients with symptomatic WS; spindles were poorly observed after age one.

In patients who lack sleep spindles, they may have never evolved or been destroyed by hypsarrhythmia. In severe brain damage sleep spindles probably never fully evolve. A less severe form of brain damage and a more favourable prognosis can be considered, if spindles are observed [20]. The expected poor prognosis due to the severe brain damage can become poorer with already high HPI levels. Multifocal activity and other seizures are other markers of poor prognosis that often precede the onset of hypsarrhythmia [1,28]. If based on these findings, an early diagnosis of WS is achieved; hypsarrhythmia can be identified and treated more efficiently before dHPI reaches $100 \%$.

When the time necessary to reach a dHPI level of $100 \%$ is considered, we can conclude that at least 2-3 months until referral are spent with heavy hypsarrhythmia stress. Some researchers have shown that even short durations of infantile spasms (in cryptogenic cases as well) can cause brain damage [6]. We have previously displayed the progressively rising HPI prior to the onset of spasms [8] and others associate persistence or long duration of hypsarrhythmia with poor developmental outcome $[10,29]$. We believe that this level of hypsarrhythmia blocks the generation of sleep spindles. Determining how long continuous hypsarrhythmia has been affecting the brain is not always straightforward. The presence, reappearance, or absence of spindles can facilitate such a determination.

Restoration of sleep spindles has been shown in studies related to other disorders [17,21,30,31]. A critical point for dHPI where spindles are no longer generated may be $60 \%$. In patients with relatively better outcome, spindles disappear with high HPI and reappear with low HPI during the follow-up.

Recurrence of hypsarrhythmia and spasms are associated with poor prognosis [3,9]. Prevention of IS relapse by keeping cHPI under $3 / \mathrm{min}$ may lead to the continuing generation or reappearance of sleep spindles. If sleep spindles are not observed despite the disappearance of hypsarrhythmia, one can expect a poor developmental outcome. Given that the spindle generating ability is related to HPI, we may also conclude that the encephalopathy is caused by the hypsarrhythmia and not by the spasms. This makes EEG abnormalities the treatment target.

Our study has some limitations. Because of its retrospective nature, the lack of a control group, and the limited number of subjects, caution should be exercised in interpreting our results and generalizing from them. Our findings could have been more robust if there had been patients with normal development or mild outcomes in the symptomatic group; such subjects have been reported on in the literature $[4,27]$.

Many parameters associated with WS outcomes have been studied, but the underlying brain dysfunction is considered to be the major determinant of later neurodevelopmental prognosis [1,2]. The specific etiology has limited value in guiding treatment. IS recurrence may be more informative. However, monitoring HPI and preventing the IS- 
triggering hypsarrhythmia will enable not only favourable treatment outcomes but also more confident outcome predictions. Our recent study [8] and others [32] have used EEG to evaluate treatment response and guide treatment. Although clinical parameters are usually preferred in outcome research on infantile spasms, studies investigating the association between EEG parameters and prognostic outcome are also found in the literature [9,10,12]. This study underlines the importance of EEG in studies of prognosis in infantile spasms; the concurrent evaluation of sleep spindles and HPI enables a more quantitative and objective assessment. Future studies with larger, controlled samples could further explore the relationship between HPI, sleep spindles, and outcome.

\section{References}

1. Appleton RE (2001) West syndrome: long-term prognosis and social aspects. Brain Dev 23:688-691.

2. Mohamed BP, Scott RC, Desai N, Gutta P, Patil S (2011) Seizure outcome in infantile spasms-a retrospective study. Epilepsia 52: 746-752.

3. Riikonen $\mathrm{R}(2001)$ Long-term outcome of patients with West syndrome Brain Dev 23: 683-687.

4. Guzzetta F, Cioni G, Mercuri E, Fazzi E, Biagioni E, et al. (2008) Neurodevelopmental evolution of West syndrome: a 2-year prospective study.Eur J Paediatr Neurol 12: 387-397.

5. Kivity S, Lerman P, Ariel R, Danziger Y, Mimouni M, et al. (2004) Longterm cognitive outcomes of a cohort of children with cryptogenic infantile spasms treated with high-dose adrenocorticotropic hormone. Epilepsia 45: 255-262.

6. Lagae L, Verhelst H, Ceulemans B, De Meirleir L, Nassogne MC, et al. (2010) Treatment and long term outcome in West syndrome: the clinical reality. A multicentre follow up study. Seizure 19: 159-164.

7. Widjaja E, Go C, McCoy B, Snead OC (2015) Neurodevelopmental outcome of infantile spasms: A systematic review and meta-analysis. Epilepsy Res 109: 155-162.

8. Altunel A, Sever A, Altunel EÖ (2015) Hypsarrhythmia paroxysm index: A tool for early prediction of infantile spasms. Epilepsy Res 111: 54-60.

9. Boulloche J, Dautreme P, Le Luyer B, Mallet E, Tron P (1991) A prognostic study of cryptogenic infantile spasms. Ann Pediatr (Paris) 38: 71-74.

10. De Menezes MA, Rho JM (2002) Clinical and electrographic features of epileptic spasms persisting beyond the second year of life. Epilepsia 43: 623-630.

11. O'Callaghan FJ, Lux AL, Darke K, Edwards SW, Hancock E, et al. (2011) The effect of lead time to treatment and of age of onset on developmental outcome at 4 years in infantile spasms: evidence from the United Kingdom Infantile Spasms Study. Epilepsia 52: 1359-1364.

12. Dulac O, Plouin P, Jambaque I, Motte J (1986) Benign epileptic infantile spasms. Rev Electroencephalogr Neurophysiol Clin 16: 371-382.

13. Mori K, Hashimoto T, Tayama M, Miyazaki M, Fukuda K, et al. (1994) Serial EEG and sleep polygraphic studies on lissencephaly (agyriapachygyria). Brain Dev 16: 365-373.

14. Nader RS, Smith CT (2015) Correlations between adolescent processing speed and specific spindle frequencies. Front Hum Neurosci 9: 30.

15. Metcalf DR and Jordan K (1972) EEG ontogenesis in normal children, in: Smith WL (Ed), Drug, Development and Cerebral function, Charles C. Thomas publisher, Springfield, Illinois.
16. Hagne I (1972) Development of the EEG in normal infants during the first year of life. A longitudinal study. Acta Paediatr Scand Suppl 232: 153.

17. Chéliout-Heraut F, Rubinsztajn R, Ioos C, Estournet B (2001) Prognostic value of evoked potentials and sleep recordings in the prolonged comatose state of children. Preliminary data. Neurophysiol Clin 31: 283292.

18. De Biase S, Gigli GL, Lorenzut S, Bianconi C, Sfreddo P, et al. (2014) The importance of polysomnography in the evaluation of prolonged disorders of consciousness: sleep recordings more adequately correlate than stimulus-related evoked potentials with patients' clinical status. Sleep Med 15: 393-400.

19. Bassetti CL, Aldrich MS (2001) Sleep electroencephalogram changes in acute hemispheric stroke. Sleep Med 2: 185-194.

20. György I (1983) Prognostic value of sleep analysis in newborns with perinatal hypoxic brain injury. Acta Paediatr Hung 24: 1-6.

21. De Giorgis GF, Nonnis E, Crocioni F, Gregori P, Rosini MP, et al. (1996). Evolution of daytime quiet sleep components in early treated phenylketonuric infants. Brain Dev 18: 201-206.

22. Lustenberger C, O'Gorman RL, Pugin F, Tüshaus L, Wehrle F, et al. (2015) Sleep spindles are related to schizotypal personality traits and thalamic glutamine/glutamate in healthy subjects. Schizophr Bull 41: 522-531.

23. Shibagaki M, Kiyono S, Watanabe K, Hakamada S (1982) Concurrent occurrence of rapid eye movement with spindle burst during nocturnal sleep in mentally retarded children. Electroencephalogr Clin Neurophysiol 53: 27-35.

24. Chatburn A, Coussens S, Lushington K, Kennedy D, Baumert M, et al. (2013) Sleep spindle activity and cognitive performance in healthy children. Sleep 36: 237-243.

25. Ferrarelli F, Tononi G (2011) The thalamic reticular nucleus and schizophrenia. Schizophr Bull 37: 306-315.

26. Rauchs G, Schabus M, Parapatics S, Bertran F, Clochon P, et al. (2008) Is there a link between sleep changes and memory in Alzheimer's disease? Neuroreport 19: 1159-1162.

27. Glaze DG, Hrachovy RA, Frost JD, Kellaway P, Zion TE (1988) Prospective study of outcome of infants with infantile spasms treated during controlled studies of ACTH and prednisone. J Pediatr 112: 389396.

28. Hamano S, Yoshinari S, Higurashi N, Tanaka M, Minamitani M, et al (2007) Developmental outcomes of cryptogenic West syndrome. J Pediatr 150: 295-299.

29. Primec ZR, Stare J, Neubauer D (2006) The risk of lower mental outcome in infantile spasms increases after three weeks of hypsarrhythmia duration. Epilepsia 47: 2202-2205.

30. Fukuyama Y, Hayashi M (1979) Sleep electroencephalograms and sleep stages in hypoparathyroidism. Eur Neurol 18: 38-48.

31. Hermann DM, Siccoli M,Brugger P, Wachter K, Mathis J, et al. (2008) Evolution of neurological, neuropsychological and sleep-wake disturbances after paramedian thalamic stroke. Stroke 39: 62-68.

32. Vacca G, de Falco FA, Natale S, del Giudice E, Romano A, et al. (1992) EEG findings in West syndrome a follow-up of 20 patients. Acta Neurol (Napoli) 14: 297-303. 